\title{
Are ankylosing spondylitis, psoriatic arthritis and undifferentiated spondyloarthritis associated with an increased risk of cardiovascular events? A prospective nationwide population-based cohort study
}

Karin Bengtsson ${ }^{1 *}\left(\mathbb{D}\right.$, Helena Forsblad-d'Elia ${ }^{1,2}$, Elisabeth Lie', Eva Klingberg ${ }^{1}$, Mats Dehlin ${ }^{1}$, Sofia Exarchou ${ }^{3}$, Ulf Lindström ${ }^{1}$, Johan Askling ${ }^{4}$ and Lennart T. H. Jacobsson ${ }^{1}$

\begin{abstract}
Background: To investigate the risk of first-time acute coronary syndrome (ACS), stroke and venous thromboembolism (VTE) in patients with ankylosing spondylitis (AS), psoriatic arthritis (PsA) and undifferentiated spondyloarthritis (USpA), compared to each other and to the general population (GP).

Methods: This is a prospective nationwide cohort study. Cohorts with AS ( $n=6448)$, PsA $(n=16,063)$ and uSpA ( $n$ $=5190)$ patients and a GP $(n=266,435)$ cohort, were identified 2001-2009 in the Swedish National Patient and Population registers. The follow-up began 1 January 2006, or 6 months after the first registered spondyloarthritis (SPA) diagnosis thereafter, and ended at ACS/stroke/NTE event, death, emigration or 31 December 2012. Crude and age- and sex-standardized incidence rates (SIRs) and hazard ratios (HRs) were calculated for incident ACS, stroke or VTE, respectively.
\end{abstract}

Results: Standardized to the GP cohort, SIRs for ACS were 4.3, 5.4 and 4.7 events per 1000 person-years at risk in the AS, PsA and USpA cohort, respectively, compared to 3.2 in the GP cohort. SIRs for stroke were 5.4, 5.9 and 5.7 events per 1000 person-years at risk in the AS, PsA and USpA cohort compared to 4.7 in the GP cohort. Corresponding SIRs for VTE were 3.6, 3.2 and 3.5 events per 1000 person-years at risk compared to 2.2 in the GP cohort. Age-and sex-adjusted HRs $(95 \% \mathrm{Cl})$ for ACS events were significantly increased in AS (1.54 (1.31-1.82)), PsA (1.76 (1.59-1.95)) and uSpA (1.36 (1.05-1.76)) compared to GP. Age-adjusted HRs for ACS was significantly decreased in female AS patients (0.59 (0.37-0.97)) compared to female PsA patients. Age-and sex-adjusted HRs for stroke events were significantly increased in AS (1.25 (1.06-1.48)) and PSA (1.34 (1.22-1.48)), and nonsignificantly increased in USpA (1.16 (0.91-1.47)) compared to GP. For VTE the age-and sex-adjusted HRs for AS, PSA and uSpA were equally and significantly increased with about 50\% compared to GP.

Conclusions: Patients with AS, PSA and USpA are at increased risk for ACS and stroke events, which emphasizes the importance of identification of and intervention against cardiovascular risk factors in SpA patients. Increased alertness for VTE is warranted in patients with SpA.

Keywords: Ankylosing spondylitis, Psoriatic arthritis, Undifferentiated spondyloarthritis, Spondyloarthritis, Spondylarthropathies, Cardiovascular disease, Cohort, Acute coronary syndrome, Stroke, Venous thromboembolism

\footnotetext{
* Correspondence: karin.si.bengtsson@vgregion.se

'Department of Rheumatology and Inflammation Research, Institute of

Medicine, Sahlgrenska Academy at University of Gothenburg, Box 48040530

Gothenburg, Sweden

Full list of author information is available at the end of the article
} 


\section{Background}

Spondyloarthritis (SpA) is a group of rheumatic diseases with a spectrum of well-defined clinical features, which include inflammatory back pain, inflammation of the sacroiliac joints, peripheral synovitis, enthesitis, psoriasis, inflammatory bowel disease and anterior uveitis [1].

In contrast to rheumatoid arthritis (RA), cardiovascular risk in SpA is less investigated. The risk of cardiovascular disease (CVD) in SpA was raised as a gap of knowledge in the recently updated European League Against Rheumatism (EULAR) recommendations for CVD management in patients with RA and other forms of inflammatory joint disorders [2]. Studies have indicated that ankylosing spondylitis (AS) is associated with an increased risk of cardiovascular morbidity and mortality, but the results have been divergent [3-10]. Psoriasis has been associated with an increased risk of stroke, myocardial infarction as well as venous thromboembolism (VTE) [11-16]. A study of non-fatal CVD in women with psoriasis found that women with concomitant psoriatic arthritis (PsA) had particularly high risk of non-fatal CVD, which is in line with studies focusing on PsA where an increased risk of CVD has been shown [17-19]. In addition, a higher burden of traditional CVD risk factors as well as increased subclinical atherosclerosis have been observed in AS and PsA patients compared to controls [10, 20-28].

We have previously compared the occurrence of different cardiovascular phenotypes in RA and AS. We found that AS patients had a $30-50 \%$ increased risk of incident cardiovascular events compared to general population. When compared to RA patients the level of increase was similar for stroke, but only half as high for acute coronary syndrome (ACS) and venous thromboembolic events [9]. The aim of this study was to extend these assessments of risks for defined cardiovascular phenotypes across different SpA subtypes, and specifically to compare risks in AS, PsA, and undifferentiated $\mathrm{SpA}$ (uSpA) to each other and to the general population.

\section{Methods}

\section{Study design and register sources}

This is a prospective nationwide population-based cohort study, including three separate cohorts of patients with AS, PsA, and uSpA identified from the Swedish National Patient Register (NPR) and one general population (GP) cohort identified from the Swedish Population Register. Through the unique personal identification number of each Swedish resident, the subjects were linked to the NPR, the Population Register, Swedish Rheumatology Quality Register (SRQ), the Swedish Prescribed Drug Register (PDR), and Statistics Sweden to identify cardiovascular outcomes as well as sociodemographic data, comorbidities and pharmacological treatment in order to characterize the populations.
The NPR was established in 1964 and contains data of inpatient care, from 1987 with full national coverage. Non-primary outpatient care has been included in the register from 2001. Primary and secondary diagnoses reported by the physician are recorded at each visit according to the International Classification of Diseases (ICD).

The Swedish Population Register holds information of residency, immigration, emigration and deaths for all the Swedish residents.

The PDR started July 2005 and contains information regarding dispensed prescriptions of pharmacological treatment, registered according to the Anatomical Therapeutic Chemical Classification (ATC) system.

The SRQ started in 1995 and includes information on treatment with biological disease-modifying antirheumatic drugs (bDMARDs) from 1999.

The research was performed with the ethical approval of the Regional Ethics Committee, Stockholm, Sweden, and has been carried out in compliance with the Helsinki declaration. Informed consent was not needed due to the register-based study design.

\section{Study populations}

This study is part of a large-scale nationwide register linkage project, which identified all patients with a registered diagnosis of AS, PsA or uSpA, given at a visit to a physician, in the NPR from 1968 through 2009. From the Population Register up to five controls per patient were identified, matched on birth-year, sex and place of residence at the date the index patient received the first SpA diagnosis in the NPR.

\section{AS, PsA, and uSpA cohorts}

From these larger groups of SpA patients, we selected all patients with at least one physician visit with an AS, PsA or $\mathrm{uSpA}$ diagnosis in rheumatology or internal medicine outpatient care between 2001 and 2009, at the ages 18 to 99 years, alive and living in Sweden at start of follow-up. These patients were included in either of the AS $(n=$ 6448), PsA $(n=16,063)$ or uSpA $(n=5190)$ cohorts. Patients with a diagnosis of RA or systemic lupus erythematosus in rheumatology or internal medicine outpatient care between 2001 and 2009 were excluded.

The ICD codes used in the identification process are shown in Additional file 1. The ICD codes for AS, PsA, and $\mathrm{uSpA}$ have previously been validated and shown to have high positive predictive values (PPVs) when compared to established classification criteria $[29,30]$. In patients with AS and available data of imaging and/or HLA-B27 status, the PPVs for fulfilling the modified New York criteria and any set of SpA criteria were $80 \%$ and 97\%, respectively. The corresponding PPVs in $\mathrm{uSpA}$ patients were $26 \%$ and $89 \%$, respectively. Undifferentiated $\mathrm{SpA}$ encompassed both axial $\mathrm{SpA}$ as well as 
peripheral SpA [29]. The PPVs of an ICD code for PsA within primary or specialized care was within the range of $63 \%$ to $92 \%$, where the highest proportion of confirmed PsA were noted if the PsA was diagnosed in specialized care (as the PsA patients in the present study) and at least on two occasions [30].

\section{Patients with $\geq 2$ subtypes of $\mathrm{SpA}$}

Patients diagnosed with more than one of the three studied SpA subtypes before start of follow-up were not included in the AS, PsA, and USpA cohorts but analyzed separately to avoid case mixing $(n=1082)$.

\section{General population cohort}

All initially identified GP controls from the first register extraction, at the ages 18 to 99 years, alive and living in Sweden at start of follow-up, were included in the GP cohort $(n=266,435)$ and used as unmatched GP comparator subjects. GP comparator subjects were excluded from the GP cohort if they were identified in any of the SpA cohorts before start of follow-up $(n=340)$.

\section{Follow-up}

The follow-up began 1 January 2006 for subjects identified prior to 30 June 2005. For subjects identified later than 30 June 2005, the follow-up began 6 months after the date of the first registered SpA diagnosis in rheumatology or internal medicine outpatient care. We chose 1 January 2006 to identify contemporary cohorts and to enable use of data from the PDR (which started July 2005). The lag period of 6 months was used to avoid detection bias, with the cardiovascular outcome of interest being a consequence of increased surveillance in connection with the SpA diagnosis. For GP comparators the follow-up began 1 January 2006 or the date of immigration if this occurred later than 1 January 2006.

All subjects were followed until first occurrence of cardiovascular outcome, emigration, death or 31 December 2012, whichever occurred first. Subjects were censored in the GP cohort if diagnosed with a SpA diagnosis and subsequently eligible to enter the corresponding SpA cohort. Patients were censored from their original SpA cohort if diagnosed with a second $\mathrm{SpA}$ subtype during follow-up and subsequently eligible to enter the SpA cohort with $\geq 2$ subtypes of SpA (described above).

\section{Baseline characteristics}

SpA-related comorbidities (anterior uveitis, psoriasis, and inflammatory bowel disease), cardiovascular comorbidities (ischemic heart disease, stroke, VTE, atrial fibrillation/flutter, other atherosclerotic disease), diabetes and chronic obstructive pulmonary disease (COPD) were regarded as prevalent at baseline if the specified ICD codes (see Additional file 1) were identified in the NPR before start of follow-up. Pharmacological treatment at baseline was defined as a dispensed prescription within 6 months before start of follow-up according to specified ATC codes in the PDR (Additional file 1). We also linked data from SRQ for the intravenous TNF inhibitor infliximab since infliximab is administered in a hospital setting and therefore not registered in the PDR. From the Statistics Sweden, we retrieved the highest level of education as a measure of socioeconomic status.

\section{Definition of cardiovascular outcome}

The primary outcomes were incident ACS, stroke, and VTE. Each outcome was analyzed separately. The primary outcomes were identified in NPR and defined as follows:

1. First occurrence of ACS (including acute myocardial infarction and unstable angina), reported as a primary discharge diagnosis from inpatient care.

2. First occurrence of stroke, reported as a primary or secondary discharge diagnosis from inpatient care. In the primary analysis we used a composite stroke outcome, consisting of both ischemic, hemorrhagic, unspecified stroke and transient ischemic attack (TIA). As secondary outcomes ischemic stroke, hemorrhagic stroke and TIA were analyzed separately.

3. First occurrence of VTE reported as a primary or secondary diagnosis from either inpatient or outpatient care.

The ICD codes used to identify the outcomes are described in Additional file 1. Importantly, subjects with a history of the cardiovascular outcome of interest prior to start of follow-up were excluded from that specific analysis. Such exclusion was based on both primary and secondary diagnoses in outpatient and inpatient care.

\section{Statistical analyses}

Descriptive statistics are presented as number (percentage) or mean \pm standard deviation (SD). For each cardiovascular outcome incidence rates, overall and stratified by sex, were calculated from the number of incident cardiovascular events and person-years at risk. To enable comparison between the cohorts, standardized rates were calculated, using the age and sex distribution in the GP cohort as standard. For the risk assessment age- and sex-adjusted hazard ratios (HRs) were calculated using Cox proportional hazard regression analyses. The largest SpA cohort - the PsA cohort - was used as the reference population in the comparison between the SpA cohorts. The proportional hazards assumption for the Cox regression analyses were evaluated graphically in survival curves and was considered fulfilled in all cases. Where applicable, 95\% confidence intervals $(\mathrm{CI})$ are reported. For 
incidence rates we have assumed a Poisson distribution when estimating 95\% CI. Additionally, age- and sexstandardized prevalence and corresponding prevalence ratio (PR) with 95\% CI for prior ACS, stroke, and VTE before start of follow-up were calculated for each SpA cohort, using the age and sex distribution in the GP cohort as standard/reference. Statistical analyses were performed by PASW Statistics version 19 (SPSS Inc., Chicago, IL, USA) and SAS Version 9.3 (SAS Institute Inc., Cary, NC, USA).

\section{Results}

\section{Study population}

We identified cohorts of AS $(n=6448)$, PsA $(n=16,063)$ and uSpA $(n=5190)$ patients and one with GP comparators $(n=266,435)$. Baseline characteristics are described in Table 1. As expected, the AS cohort had a larger proportion of men compared to the other cohorts. In the PsA cohort 41.5\% had current disease-modifying antirheumatic drugs (DMARDs) at baseline compared to $24.8 \%$ and $30.4 \%$ in the AS and uSpA cohort, respectively. Approximately 50\% in all of the SpA cohorts were exposed to nonsteroidal antiinflammatory drugs (NSAIDs) at baseline. The uSpA cohort had the youngest mean age and had overall lower frequencies of previous cardiovascular comorbidity and dispensed prescription of drugs related to CVD. Age- and sex-standardized PRs of prior ACS, stroke, and VTE were increased in all of the SpA cohorts compared to the GP cohort (Additional file 2). The subjects with a prior ACS, stroke and VTE at baseline were excluded from the ACS, stroke and VTE outcome analysis, respectively.

The mean overall time of follow-up (SD) was 5.6 (1.9) years for AS patients, 5.7 (1.6) years for PsA patients, 5.4 (2.0) years for uSpA patients, and 6.7 (1.2) years for GP comparators.

\section{Acute coronary syndrome}

During follow-up, 143, 420, and 59 incident ACS events occurred in the AS, PsA, and uSpA cohorts, respectively, resulting in standardized incidence rates of $4.3,5.4$, and 4.7 ACS events per 1000 person-years at risk compared to 3.2 in the GP cohort (Table 2). The incidence rates were overall lower for women than men. The age- and sex-adjusted HRs were significantly increased in AS (1.54 (1.31-1.82)), PsA (1.76 (1.59-1.95), and uSpA (1.36 (1.05-1.76)) compared to the GP cohort. In the sex-stratified analyses, the highest age-adjusted HR point estimate was noted for female PsA patients $(1.96(1.68-2.29))$ compared to the female GP cohort. Female PsA patients also had an increased risk of ACS compared to female AS patients (Fig. 1).

\section{Stroke}

During follow-up, 147, 463, and 66 incident composite stroke events occurred in the AS, PsA, and uSpA cohorts, respectively, resulting in standardized incidence rates of 5.4,
5.9, and 5.7 stroke events per 1000 person-years at risk compared to 4.7 in the GP cohort (Table 2). The age- and sex-adjusted HRs were significantly increased in AS (1.25 $(1.06-1.48))$ and PsA (1.34 (1.22-1.48)) and nonsignificantly in uSpA (1.16 (0.91-1.47)) patients compared to the GP cohort. There were no significant differences between AS and uSpA compared to the PsA cohort (Fig. 2).

The results for ischemic stroke were similar to those for stroke as a composite outcome. When TIA was used as an outcome, significantly increased HRs were noted in PsA and USpA, and nonsignificantly in AS compared to GP. In contrast, no significant differences in HRs were noted for hemorrhagic stroke (Fig. 3).

\section{Venous thromboembolism}

Based on 98, 268 and 56 incident VTE in the AS, PsA, and $\mathrm{uSpA}$ cohort, respectively, the standardized incidence rates were 3.6, 3.2, and 3.5 VTE events per 1000 person-years at risk compared to 2.2 in the GP cohort (Table 2). The HRs were significantly increased by around $50 \%$ in all of the three SpA cohorts compared to the GP cohort, both overall and stratified by sex, with the exception of male PsA patients (Fig. 4).

\section{Patients diagnosed with $\geq 2$ subtypes of $S p A$}

Patients $(n=1931)$ excluded prior to study entry or censored during follow-up based on ICD codes for two or more of the three different SpA subtypes were analyzed separately. These patients ( $55 \%$ men, mean age 45.2 years) were to a larger extent treated with DMARD (48.2\%) and TNF inhibitors (20.1\%) at baseline (Additional file 3). The majority of the patients $(n=1169)$ had an overlap of AS and $\mathrm{USpA}$ diagnoses. Incidence rates and HRs for the cardiovascular outcomes are summarized in Additional file 3 and did not diverge substantially from the main results.

\section{Discussion}

In this nationwide prospective population-based cohort study we found an increased risk of $36-76 \%$ for ACS and $50 \%$ for VTE in all subtypes of SpA compared to the general population. A less pronounced, but still increased risk was noted for stroke in AS and PsA, but not in uSpA. Female PsA patients had an almost doubled risk of having a first-time ACS compared to GP comparators as well as a significantly increased risk compared to female AS patients. Apart from this, no statistically significant differences in cardiovascular events were found between the SpA cohorts, although the PsA patients tended to have the highest risks for both stroke and ACS. The absolute risks of ACS, VTE, and stroke were modest in all cohorts, as would be expected considering the relatively low mean age of the cohorts.

In relation to other studies, our results in PsA are similar to the risk estimates for myocardial infarction 
Table 1 Baseline characteristics of patients with AS, PsA, USpA and GP comparators at start of follow-up

\begin{tabular}{|c|c|c|c|c|}
\hline & $\operatorname{AS}(n=6448)$ & PsA $(n=16,063)$ & uSpA $(n=5190)$ & $\mathrm{GP}(n=266,435)$ \\
\hline \multicolumn{5}{|l|}{ Sex } \\
\hline Males & $4390(68.1)$ & $7217(44.9)$ & $2325(44.8)$ & $131,807(49.5)$ \\
\hline Females & 2058 (31.9) & $8846(55.1)$ & $2865(55.2)$ & $134,628(50.5)$ \\
\hline \multicolumn{5}{|l|}{ Age (years) } \\
\hline Mean (SD) & $50.0(13.9)$ & $53.2(13.8)$ & $44.7(13.3)$ & $53.5(15.9)$ \\
\hline $18-29$ years & $488(7.6)$ & $761(4.7)$ & $691(13.3)$ & $18,465(6.9)$ \\
\hline 30-39 years & $1120(17.4)$ & 2047 (12.7) & $1255(24.2)$ & $36,805(13.8)$ \\
\hline 40-49 years & $1452(22.5)$ & $3368(21.0)$ & $1406(27.1)$ & $52,122(19.6)$ \\
\hline 50-59 years & $1670(25.9)$ & $4385(27.3)$ & $1085(20.9)$ & $63,559(23.9)$ \\
\hline $60-69$ years & 1209 (18.8) & $3638(22.6)$ & $583(11.2)$ & $52,626(19.8)$ \\
\hline 70-79 years & $414(6.4)$ & $1422(8.9)$ & $132(2.5)$ & $27,259(10.2)$ \\
\hline$\geq 80$ years & $95(1.5)$ & $442(2.8)$ & $38(0.7)$ & $15,599(5.9)$ \\
\hline \multicolumn{5}{|l|}{ Start of follow-up } \\
\hline 2006-2007 & 4938 (76.6) & $11,926(74.2)$ & $3725(71.8)$ & 266,234 (99.9) \\
\hline 2008-2010 & $1510(23.4)$ & $4137(25.8)$ & $1465(28.2)$ & $201(0.1)$ \\
\hline \multicolumn{5}{|l|}{ Level of education } \\
\hline$-\leq 9$ years & $1423(22.1)$ & $4039(25.1)$ & $804(15.5)$ & $68,776(25.8)$ \\
\hline$-10-12$ years & $3096(48.0)$ & $7983(49.7)$ & $2566(49.4)$ & $119,681(44.9)$ \\
\hline$->12$ years & $1858(28.8)$ & 3931 (24.5) & 1789 (34.5) & $74,587(28.0)$ \\
\hline -Missing & $71(1.1)$ & $110(0.7)$ & $31(0.6)$ & 3391 (1.3) \\
\hline \multicolumn{5}{|l|}{ SpA-related comorbidities ${ }^{a}$} \\
\hline Anterior uveitis & $1342(20.8)$ & $252(1.6)$ & $771(14.9)$ & $1156(0.4)$ \\
\hline Inflammatory bowel disease & $514(8.0)$ & $346(2.2)$ & $269(5.2)$ & $2565(1.0)$ \\
\hline Psoriasis & $145(2.2)$ & $15,873(98.8)$ & $162(3.1)$ & $2190(0.8)$ \\
\hline \multicolumn{5}{|l|}{ SpA-related medications ${ }^{b}$} \\
\hline Any DMARD & $1599(24.8)$ & $6659(41.5)$ & 1579 (30.4) & $2542(1.0)$ \\
\hline -TNF inhibitors & $545(8.5)$ & $758(4.7)$ & $279(5.4)$ & $268(0.1)$ \\
\hline -Methotrexate & $494(7.7)$ & $5094(31.7)$ & $609(11.7)$ & $1104(0.4)$ \\
\hline -Sulfasalazin & $798(12.4)$ & $1396(8.7)$ & $877(16.9)$ & $493(0.2)$ \\
\hline NSAIDs & $3543(54.9)$ & 7801 (48.6) & $2804(54.0)$ & $28,467(10.7)$ \\
\hline Prednisone & $659(10.2)$ & $2133(13.3)$ & $778(15.0)$ & $4234(1.6)$ \\
\hline \multicolumn{5}{|l|}{ Other comorbidities ${ }^{a}$} \\
\hline Ischemic heart disease & $468(7.3)$ & $1091(6.8)$ & $182(3.5)$ & $14,849(5.6)$ \\
\hline$-A C S$ & $256(4.0)$ & $576(3.6)$ & $94(1.8)$ & $8714(3.3)$ \\
\hline Composite stroke & $201(3.1)$ & $527(3.3)$ & $84(1.6)$ & $8954(3.4)$ \\
\hline -Ischemic stroke & $92(1.4)$ & $265(1.6)$ & $49(0.9)$ & 5009 (1.9) \\
\hline -Hemorrhagic stroke & $41(0.6)$ & $100(0.6)$ & $14(0.3)$ & $1412(0.5)$ \\
\hline$-T I A$ & $77(1.2)$ & $185(1.2)$ & $28(0.5)$ & $2951(1.1)$ \\
\hline Venous thromboembolism & $115(1.8)$ & $347(2.2)$ & $80(1.5)$ & $3835(1.4)$ \\
\hline Diabetes & $311(4.8)$ & $1025(6.4)$ & $144(2.8)$ & $10,118(3.8)$ \\
\hline COPD & $122(1.9)$ & $317(2.0)$ & $48(0.9)$ & $3507(1.3)$ \\
\hline Atrial fibrillation or flutter & $264(4.1)$ & $513(3.2)$ & $87(1.7)$ & $7430(2.8)$ \\
\hline Other atherosclerotic disease & $210(3.3)$ & $581(3.6)$ & $101(1.9)$ & $8318(3.1)$ \\
\hline
\end{tabular}


Table 1 Baseline characteristics of patients with AS, PsA, uSpA and GP comparators at start of follow-up (Continued)

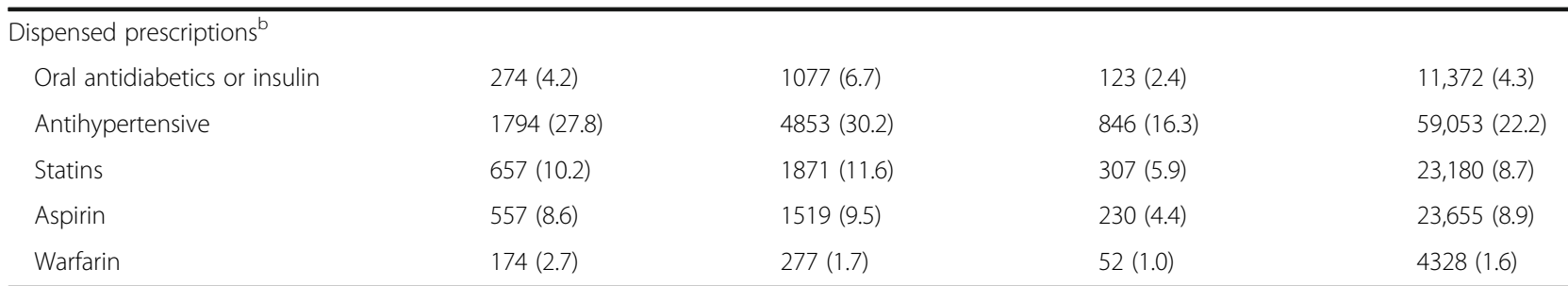

Age are given in mean (SD). All other data are presented in number (\%)

AS ankylosing spondylitis, PSA psoriatic arthritis, USpA undifferentiated spondyloarthritis, GP general population, DMARD disease-modifying antirheumatic drug,

NSAIDs nonsteroidal anti-inflammatory drugs, ACS acute coronary syndrome, TIA transient ischemic attack, COPD chronic obstructive pulmonary disease

aPrevalent comorbidity at baseline, defined by identification of specified ICD codes in the National Patient Register prior to start of follow-up

${ }^{\mathrm{b}}$ Dispensed prescription in Prescribed Drug Register or intravenous bDMARDs in Swedish Rheumatology Quality register within 6 months prior to start of follow-up

found in severe psoriasis and somewhat lower than the risk estimates for stroke in severe psoriasis according to a meta-analysis from 2013 [11]. Two previous studies have investigated incident major adverse cardiovascular events (MACE), which include myocardial infarction and stroke, in PsA patients. We found a similar relative risk of stroke in PsA and a slightly higher relative risk of ACS/myocardial infarction compared to the British study using a primary health-care database to identify PsA patients and cardiovascular outcomes [17]. Li et al., using another British primary health-care database, only reports results of the composite outcome MACE and found an incidence rate ratio of 1.30 (95\% CI 1.15-1.47) in PsA patients compared to patients without PsA [18]. Previous studies in AS have shown divergent results. Two prior studies, using different British primary health-care databases to identify patients with ankylosing spondylitis, did not find an increased risk of myocardial infarction or stroke $[6,7]$. However, Keller et al. found a more than doubled risk of stroke in AS [4]. This is in contrast to our risk estimates, which are in agreement to Chou et al. who found an increased risk of ACS with HRs 1.36 (1.16-1.59) [5]. Possible explanations for these divergent results could be selection of patients and validity of outcome assessments. Our study is populationbased, with case ascertainment based on diagnoses set by specialists in rheumatology or internal medicine. This together with the generally well-validated National $\mathrm{Pa}$ tient Register, and the large patient groups, support the accuracy of the present results [31].

Results regarding VTE risks in SpA patients are scarce. A register-based Danish study found an even higher risk increase of VTE in patients with severe psoriasis compared to our findings [12]. However, in our study male PsA patients, in contrast to the other SpA patients, did not have a significantly increased risk of VTE compared to GP. Increased risks of VTE have also been demonstrated in other chronic inflammatory diseases, such as RA and inflammatory bowel disease [32-36].
In the sub-analysis of different types of stroke, the relative risk estimates were similar for composite stroke, ischemic stroke and TIA, which is not surprising considering that the latter two constitute the majority of all strokes [37]. For the minor group of stroke diagnosed as hemorrhagic stroke no differences were seen when comparing the SpA cohorts to the GP cohort. The stroke subtypes share some risk factors, such as hypertension, whereas other risk factors are more associated with one or the other, such as vascular malformations with hemorrhagic stroke and atrial fibrillation with ischemic stroke and TIA [38, 39]. Previous studies have found an association between inflammatory markers and ischemic stroke specifically, which could explain the different risks for ischemic and hemorrhagic stroke found in our study of patients with SpA patients compared to the GP cohort [40-42].

We observed increased risks in SpA patients of both arterial and venous thromboembolic events, which traditionally are considered having different risk factor panorama. Established risk factors for VTE include major surgery, malignant disease as well as multiple trauma and fractures [43, 44]. Shared risk factors for venous and arterial thromboembolism, such as obesity, diabetes and smoking, have been suggested by some, but not all studies [45-50]. Furthermore, inflammation has been suggested to be involved in both the atherosclerosis and in the VTE process and also to constitute a possible link between them $[44,51]$.

We have deliberately avoided making adjustments for other factors than age and sex since the aim was to assess rather than to attribute any increased risks of cardiovascular events seen in the SpA cohorts compared to the GP cohort. Our aim was thus not to examine to which extent inflammation, specific disease manifestations of the different SpA diagnoses or traditional CVD and VTE risk factors contributed to this increased risk. Due to the register-based design we lack detailed information on an individual level, both with regard to traditional risk factors for CVD, such as smoking habits, physical activity, body mass index and hereditary factors, as well as markers of inflammation and disease activity. Residual 
Table 2 Incidence rates of ACS, stroke and VTE in AS, PsA, USpA patients and GP comparators

\begin{tabular}{|c|c|c|c|c|}
\hline & AS & PsA & uSpA & GP \\
\hline \multicolumn{5}{|l|}{ Acute coronary syndrome } \\
\hline Subjects at risk, $\mathrm{n}$ & 6192 & 15,487 & 5096 & 257,721 \\
\hline Incident events, n (male/female) & $143(125 / 18)$ & $420(242 / 178)$ & $59(39 / 20)$ & $5480(3645 / 1835)$ \\
\hline Person-years at risk, $\mathrm{n}$ & 34,658 & 87,903 & 27,287 & $1,712,019$ \\
\hline \multicolumn{5}{|l|}{ Overall incidence rates } \\
\hline -Crude rates & $4.1(3.4-4.8)$ & $4.8(4.3-5.2)$ & $2.2(1.6-2.7)$ & \multirow[t]{2}{*}{$3.2(3.1-3.3)$} \\
\hline -Standardized rates ${ }^{a}$ & $4.3(3.4-5.2)$ & $5.4(4.8-5.9)$ & $4.7(3.1-6.2)$ & \\
\hline \multicolumn{5}{|l|}{ Male incidence rates } \\
\hline -Crude rates & $5.3(4.4-6.3)$ & $6.3(5.5-7.1)$ & $3.3(2.3-4.3)$ & \multirow[t]{2}{*}{$4.4(4.3-4.6)$} \\
\hline -Standardized rates ${ }^{b}$ & $6.3(5.1-7.5)$ & $7.0(6.1-8.0)$ & $5.9(3.7-8.0)$ & \\
\hline \multicolumn{5}{|l|}{ Female incidence rates } \\
\hline -Crude rates & $1.6(0.9-2.3)$ & $3.6(3.1-4.1)$ & $1.3(0.7-1.9)$ & \multirow[t]{2}{*}{$2.1(2.0-2.2)$} \\
\hline -Standardized rates ${ }^{\mathrm{b}}$ & $2.4(1.0-3.7)$ & $3.8(3.2-4.4)$ & $3.6(1.4-5.8)$ & \\
\hline \multicolumn{5}{|l|}{ Composite stroke } \\
\hline Subjects at risk, $\mathrm{n}$ & 6247 & 15,536 & 5106 & 257,481 \\
\hline Incident events, n (male/female) & $147(110 / 37)$ & $463(219 / 244)$ & $66(31 / 35)$ & $8001(4405 / 3596)$ \\
\hline Person-years at risk, $\mathrm{n}$ & 35,017 & 88,075 & 27343 & $1,707,096$ \\
\hline \multicolumn{5}{|l|}{ Overall incidence rates } \\
\hline -Crude rates & $4.2(3.5-4.9)$ & $5.3(4.8-5.7)$ & $2.4(1.8-3.0)$ & \multirow[t]{2}{*}{$4.7(4.6-4.8)$} \\
\hline -Standardized rates ${ }^{a}$ & $5.4(4.3-6.6)$ & $5.9(5.4-6.5)$ & $5.7(3.9-7.4)$ & \\
\hline \multicolumn{5}{|l|}{ Male incidence rates } \\
\hline -Crude rates & $4.6(3.8-5.5)$ & $5.6(4.8-6.3)$ & $2.6(1.7-3.5)$ & \multirow[t]{2}{*}{$5.3(5.1-5.4)$} \\
\hline -Standardized rates ${ }^{\mathrm{b}}$ & $5.9(4.7-7.1)$ & $6.5(5.6-7.3)$ & $5.2(2.9-7.4)$ & \\
\hline \multicolumn{5}{|l|}{ Female incidence rates } \\
\hline -Crude rates & $3.3(2.2-4.4)$ & $5.0(4.4-5.6)$ & $2.3(1.5-3.0)$ & \multirow[t]{2}{*}{$4.1(4.0-4.3)$} \\
\hline -Standardized rates ${ }^{\mathrm{b}}$ & $5.0(3.0-6.9)$ & $5.5(4.7-6.2)$ & $6.1(3.4-8.8)$ & \\
\hline \multicolumn{5}{|l|}{ Venous thromboembolism } \\
\hline Subjects at risk, $\mathrm{n}$ & 6333 & 15,716 & 5110 & 262,600 \\
\hline Incident events, n (male/female) & $98(66 / 32)$ & $268(95 / 173)$ & $56(26 / 30)$ & $3925(2038 / 1887)$ \\
\hline Person-years at risk, $\mathrm{n}$ & 35,575 & 89,525 & 27,363 & $1,745,481$ \\
\hline \multicolumn{5}{|l|}{ Overall incidence rates } \\
\hline -Crude rates & $2.8(2.2-3.3)$ & $3.0(2.6-3.4)$ & $2.0(1.5-2.6)$ & \multirow[t]{2}{*}{$2.2(2.2-2.3)$} \\
\hline -Standardized rates ${ }^{a}$ & $3.6(2.6-4.6)$ & $3.2(2.8-3.6)$ & $3.5(2.3-4.7)$ & \\
\hline \multicolumn{5}{|l|}{ Male incidence rates } \\
\hline -Crude rates & $2.7(2.1-3.4)$ & $2.4(1.9-2.8)$ & $2.2(1.3-3.0)$ & \multirow[t]{2}{*}{$2.4(2.3-2.5)$} \\
\hline -Standardized rates ${ }^{\mathrm{b}}$ & $3.0(2.2-3.8)$ & $2.6(2.1-3.2)$ & $3.1(1.8-4.4)$ & \\
\hline \multicolumn{5}{|l|}{ Female incidence rates } \\
\hline -Crude rates & $2.8(1.9-3.8)$ & $3.5(3.0-4.0)$ & $2.0(1.3-2.7)$ & \multirow[t]{2}{*}{$2.1(2.0-2.2)$} \\
\hline -Standardized rates ${ }^{b}$ & $4.2(2.4-5.9)$ & $3.7(3.2-4.3)$ & $3.9(1.9-5.9)$ & \\
\hline
\end{tabular}

Rates are presented as number of events per 1000 person-years at risk. All rates are calculated with $95 \%$ confidence interval given in parenthesis ACS acute coronary syndrome, VTE venous thromboembolism, AS ankylosing spondylitis, PSA psoriatic arthritis, USpA undifferentiated spondyloarthritis, GP general population

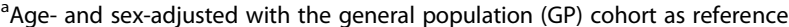

${ }^{b}$ Age-adjusted with the GP cohort as reference

${ }^{c}$ Composite stroke includes ischemic, hemorrhagic, unspecified stroke, and transient ischemic attack 


\begin{tabular}{l} 
Overall \\
AS vs General Population \\
PsA vs General Population \\
uSpA vs General Population \\
AS vs PsA \\
uSpA vs PsA \\
\hline Men \\
AS vs General Population \\
PsA vs General Population \\
uSpA vs General Population \\
AS vs PsA \\
uSpA vs PsA \\
\hline Women \\
AS vs General Population \\
PsA vs General Population \\
uSpA vs General Population \\
AS vs PsA \\
uSpA vs PsA
\end{tabular}

Fig. 1 Age- and sex-adjusted hazard ratios (HRs) for acute coronary syndrome (ACS). Age- and sex-adjusted HRs, overall and stratified by sex, are presented with 95\% confidence interval (CI) in patients with AS, PSA, and USPA, using GP comparators and PSA patients as reference. AS ankylosing spondylitis, PSA psoriatic arthritis, USPA undifferentiated spondyloarthritis

\section{Stroke}

\section{Overall}

AS vs General Population

PsA vs General Population uSpA vs General Population

AS vs PSA

uSpA vs PsA

Men

AS vs General Population PsA vs General Population uSpA vs General Population

AS vs PSA

uSpA vs PsA

\section{Women}

AS vs General Population PsA vs General Population uSpA vs General Population

AS vs PSA uSpA vs PsA

\section{$\mathrm{HR}(95 \% \mathrm{Cl})$}

$1.25(1.06-1.48)$

$1.34(1.22-1.48)$

$1.16(0.91-1.47)$

$0.95(0.79-1.15)$

$0.89(0.69-1.16)$

$1.23(1.02-1.49)$

$1.28(1.12-1.47)$

$1.06(0.75-1.52)$

$0.96(0.77-1.21)$

$0.84(0.58-1.23)$

$1.29(0.93-1.79)$

$1.41(1.23-1.60)$

$1.26(0.90-1.76)$

$0.93(0.65-1.31)$ $0.95(0.66-1.36)$

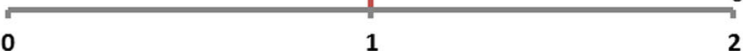

Fig. 2 Age- and sex-adjusted hazard ratios (HRs) for composite stroke. Age- and sex-adjusted HRs, overall and stratified by sex, are presented with 95\% confidence interval (CI) in patients with AS, PSA, and USPA, using GP comparators and PSA patients as reference. AS ankylosing spondylitis, PSA psoriatic arthritis, USPA undifferentiated spondyloarthritis 


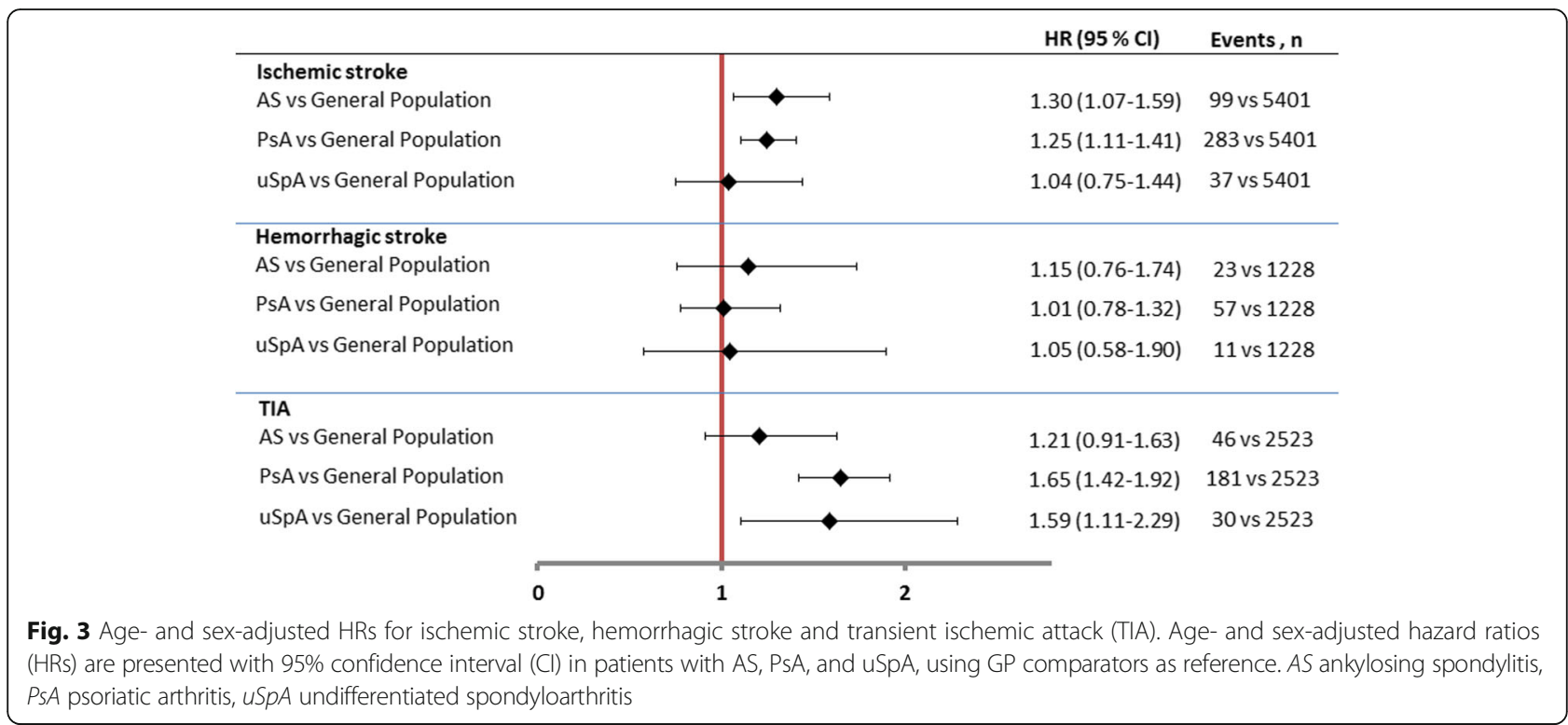

confounding factors would thus have been very likely if we had adjusted only for comorbidities and pharmacological treatment. Furthermore, since the patients had a prevalent SpA diagnosis, any differences in baseline comorbidities and treatments could also have been a consequence of previous disease manifestations. However, the increased risk for ACS and stroke found in all SpA subtypes emphasizes the importance of identification of and intervention against cardiovascular risk factors in SpA patients. These findings also support the new EULAR recommendations for CVD risk management which include recommendation of CVD risk assessment at least once every 5 years for AS and PsA patients[2].

Some limitations to the study need to be acknowledged. First, we cannot exclude misclassifications of the SpA diagnoses or the cardiovascular outcomes. The ICD codes used for both identification of AS, PsA, and uSpA

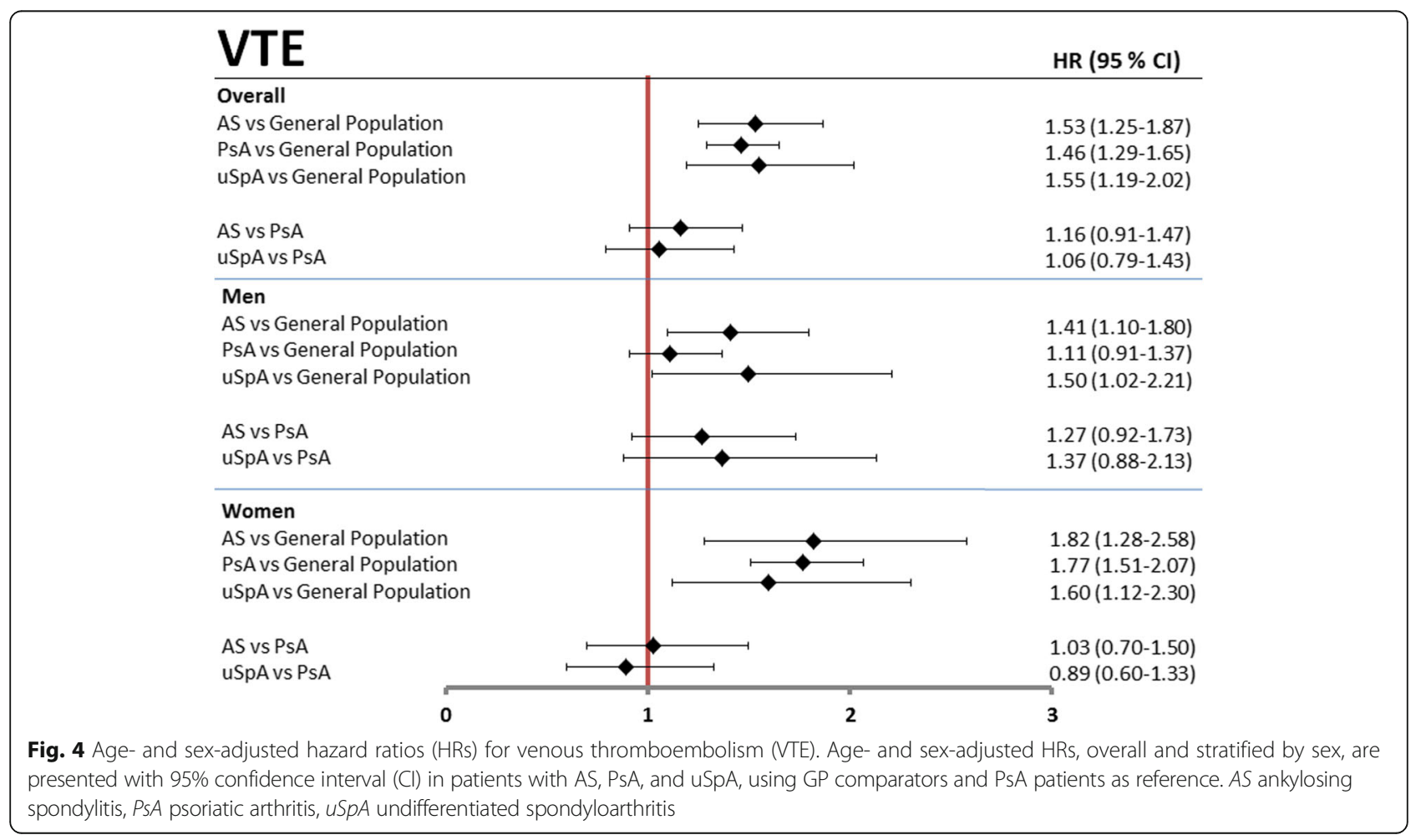


have been used in other Swedish register-based studies and AS, uSpA, PsA, ACS/myocardial infarction, ischemic and hemorrhagic stroke are validated before with high positive predictive values [29-32, 52-55]. We analyzed patients with more than one of the three studied SpA subtypes separately to avoid case mixing. Due to similarities in clinical presentation, some remaining overlapping between the SpA subtypes is probably inevitable. Second, patients with SpA solely followed in primary care, presumably patients with a less severe disease, are not identified, and this may influence the generalizability of our results. In Sweden SpA patients without DMARDs may be monitored in primary care, but are predominately diagnosed in rheumatology or internal medicine outpatient care at least once, and would thus have been identified in our study. Third, for some cardiovascular events, such as hemorrhagic stroke, the low number of events may have hampered the statistical power. In addition, we cannot exclude that the generally lower incidence rates of ACS found in women was a consequence of under-recognition of ischemic heart disease due to different clinical presentation than in men [56].

There are also several strengths to the present study. First, it is the first study to compare the risk of CVD events for the different subtypes of SpA in the same setting simultaneously and also reporting CVD outcomes in the relatively large group classified as uSpA. The uSpA is a less clearly defined subtype of SpA, where previous research about CVD risks is especially lacking. Second, it is a population-based study of health-care registers, minimizing problems with selection bias. Third, due to the registerbased approach there is negligible loss of follow-up.

\section{Conclusions}

Patients with AS, PsA, and USpA are at increased risk for ACS and stroke, which emphasizes the importance of identification of and intervention against cardiovascular risk factors in SpA patients. These findings also support the new EULAR recommendations for CVD risk management which include recommendation of CVD risk assessment at least once every 5 years for AS and PsA patients [2]. Increased alertness for VTE is warranted in patients with SpA.

\section{Additional files}

Additional file 1: List of ICD and ATC codes used to identify patients, cardiovascular events, baseline comorbidities, and pharmacological treatment. (DOCX $21 \mathrm{~kb}$ )

Additional file 2: Age- and sex-standardized prevalence and corresponding prevalence ratios (PRs) for prior ACS, stroke, and VTE for each SpA cohort, using the age and sex distribution in the GP cohort as standard/reference. (DOCX $12 \mathrm{~kb}$ )

Additional file 3: Baseline characteristics, incidence rates and HRs of ACS, stroke, and VTE in patients diagnosed with $\geq 2$ subtypes of SpA. (DOCX $20 \mathrm{~kb}$ )

\section{Abbreviations}

ACS: Acute coronary syndrome; AS: Ankylosing spondylitis; ATC: Anatomical Therapeutic Chemical Classification; bDMARDs: Biological disease-modifying antirheumatic drugs; Cl: Confidence interval; COPD: Chronic obstructive pulmonary disease; CVD: Cardiovascular disease; DMARD(s): Diseasemodifying antirheumatic drug(s); EULAR: European League Against Rheumatism; GP: General population; HRs: Hazard ratios; ICD: International Classification of Diseases; MACE: Major adverse cardiovascular events; NPR: National Patient Register; NSAIDs: Nonsteroidal anti-inflammatory drugs; PDR: Prescribed Drug Register; PPVs: Positive predictive values;

PRs: Prevalence ratios; PsA: Psoriatic arthritis; RA: Rheumatoid arthritis; SD: Standard deviation; SIRs: Standardized incidence rates;

SpA: Spondyloarthritis; SRQ: Swedish Rheumatology Quality register; TIA: Transient ischemic attack; uSpA: Undifferentiated spondyloarthritis; VTE: Venous thromboembolism

\section{Acknowledgements}

We thank Jonas Söderling for helping us with the initial extraction of the register-linked data and statistician Tatiana Zverkova Sandström for preparation of the extracted data.

\section{Funding}

This work was supported by grants from the University of Gothenburg; the Medical Society of Gothenburg; the Region Västra Götaland; Sahlgrenska University Hospital (agreement concerning research and educations of doctors); Göteborg's Association Against Rheumatism; and Swedish Rheumatism Association.

\section{Availability of data and materials}

The data sets generated and/or analyzed during the current study are not publicly available due to the Swedish legislation (the Personal Data Act), but a limited and fully anonymized data set containing the individual patient data that support the main analyses is available from the corresponding author on request.

\section{Authors' contributions}

$\mathrm{KB}$ contributed to the design of the study, data acquisition, analysis and interpretation of data and drafting the manuscript. HF contributed to the interpretation of data and drafting the manuscript. EL, EK, MD, SE, and UL contributed to the interpretation of data and have revised the manuscript critically for important intellectual content. JA contributed to the design of the study, interpretation of data and has revised the manuscript critically for important intellectual content. $\amalg J$ contributed to the design of the study, interpretation of data and drafting the manuscript. All authors have read and approved the final manuscript.

\section{Competing interests}

HF has received advisory board fees from Sandoz and Novartis and unrestricted grant from Novartis. EL has received consultancy and/or speaker honoraria from Abbvie, Celgene, Pfizer and UCB. JA has received research grants from Abbvie, AstraZeneca, Merck, Pfizer, Roche, Samsung and UCB in relation to work based on the Swedish Biologics Register ARTIS. JA reported participating in research projects fully or partly funded by Novo Nordisk. $L J$ has received advisory board fees from Abbvie, Pfizer and Novartis. All other authors declare that they have no competing interests.

Consent for publication

Not applicable.

Ethics approval and consent to participate

The research was performed with the ethical approval of the Regional Ethics Committee, Stockholm, Sweden (9 February 2011, registration number 2011/ 29-31/1), and has been carried out in compliance with the Helsinki declaration. Informed consent was not needed due to the register-based study design.

\section{Publisher's Note}

Springer Nature remains neutral with regard to jurisdictional claims in published maps and institutional affiliations. 


\section{Author details}

'Department of Rheumatology and Inflammation Research, Institute of Medicine, Sahlgrenska Academy at University of Gothenburg, Box 48040530 Gothenburg, Sweden. ${ }^{2}$ Departments of Public Health and Clinical Medicine, Rheumatology, Umeå University, 90187 Umeå, Sweden. ${ }^{3}$ Section of Rheumatology, Department of Clinical Sciences, Malmö, Lund University, 202 13 Malmö, Sweden. ${ }^{4}$ Clinical Epidemiology Unit and Rheumatology Unit, Department of Medicine Solna, Karolinska Institutet, 17177 Solna, Sweden.

Received: 7 February 2017 Accepted: 2 May 2017 Published online: 18 May 2017

\section{References}

1. Sieper J, Rudwaleit M, Khan MA, Braun J. Concepts and epidemiology of spondyloarthritis. Best Pract Res Clin Rheumatol. 2006;20:401-17.

2. Agca R, Heslinga SC, Rollefstad S, Heslinga M, Mclnnes IB, Peters MJ, et al. EULAR recommendations for cardiovascular disease risk management in patients with rheumatoid arthritis and other forms of inflammatory joint disorders: 2015/2016 update. Ann Rheum Dis. 2017;76(1):17-28. doi:10.1136/ annrheumdis-2016-209775. 6

3. Szabo SM, Levy AR, Rao SR, Kirbach SE, Lacaille D, Cifaldi M, et al. Increased risk of cardiovascular and cerebrovascular diseases in individuals with ankylosing spondylitis: a population-based study. Arthritis Rheum. 2011;63: 3294-304.

4. Keller JJ, Hsu JL, Lin SM, Chou CC, Wang LH, Wang J, et al. Increased risk of stroke among patients with ankylosing spondylitis: a population-based matched-cohort study. Rheumatol Int. 2014;34:255-63.

5. Chou CH, Lin MC, Peng CL, Wu YC, Sung FC, Kao CH, et al. A nationwide population-based retrospective cohort study: increased risk of acute coronary syndrome in patients with ankylosing spondylitis. Scand J Rheumatol. 2014;43:132-6.

6. Brophy S, Cooksey R, Atkinson M, Zhou SM, Husain MJ, Macey S, et al. No increased rate of acute myocardial infarction or stroke among patients with ankylosing spondylitis-a retrospective cohort study using routine data. Semin Arthritis Rheum. 2012:42:140-5.

7. Essers I, Stolwijk C, Boonen A, De Bruin ML, Bazelier MT, de Vries F, et al. Ankylosing spondylitis and risk of ischaemic heart disease: a populationbased cohort study. Ann Rheum Dis. 2016;75:203-9.

8. Haroon NN, Paterson JM, Li P, Inman RD, Haroon N. Patients with ankylosing spondylitis have increased cardiovascular and cerebrovascular mortality: a population-based study. Ann Intern Med. 2015;163:409-16.

9. Eriksson JK, Jacobsson L, Bengtsson K, Askling J. Is ankylosing spondylitis a risk factor for cardiovascular disease, and how do these risks compare with those in rheumatoid arthritis? Ann Rheum Dis. 2017;76(2):364-70. doi:10.1136/annrheumdis-2016-209315.

10. Han C, Robinson Jr DW, Hackett MV, Paramore LC, Fraeman KH, Bala MV. Cardiovascular disease and risk factors in patients with rheumatoid arthritis, psoriatic arthritis, and ankylosing spondylitis. J Rheumatol. 2006;33:2167-72.

11. Armstrong EJ, Harskamp CT, Armstrong AW. Psoriasis and major adverse cardiovascular events: a systematic review and meta-analysis of observational studies. J Am Heart Assoc. 2013;2, e000062.

12. Ahlehoff $\mathrm{O}$, Gislason $\mathrm{GH}$, Lindhardsen J, Charlot MG, Jorgensen $\mathrm{CH}$, Olesen $J B$, et al. Psoriasis carries an increased risk of venous thromboembolism: a Danish nationwide cohort study. PLoS One. 2011;6, e18125.

13. Neimann AL, Shin DB, Wang X, Margolis DJ, Troxel AB, Gelfand JM. Prevalence of cardiovascular risk factors in patients with psoriasis. J Am Acad Dermatol. 2006;55:829-35.

14. Ahlehoff $\mathrm{O}$, Gislason $\mathrm{GH}$, Charlot M, Jorgensen $\mathrm{CH}$, Lindhardsen J, Olesen JB, et al. Psoriasis is associated with clinically significant cardiovascular risk: a Danish nationwide cohort study. J Intern Med. 2011;270:147-57.

15. Gelfand JM, Dommasch ED, Shin DB, Azfar RS, Kurd SK, Wang X, et al. The risk of stroke in patients with psoriasis. J Invest Dermatol. 2009;129:2411-8.

16. Gelfand JM, Neimann AL, Shin DB, Wang X, Margolis DJ, Troxel AB. Risk of myocardial infarction in patients with psoriasis. JAMA. 2006;296:1735-41.

17. Ogdie A, Yu Y, Haynes K, Love TJ, Maliha S, Jiang Y, et al. Risk of major cardiovascular events in patients with psoriatic arthritis, psoriasis and rheumatoid arthritis: a population-based cohort study. Ann Rheum Dis. 2015;74:326-32.

18. Li L, Hagberg KW, Peng M, Shah K, Paris M, Jick S. Rates of cardiovascular disease and major adverse cardiovascular events in patients with psoriatic arthritis compared to patients without psoriatic arthritis. J Clin Rheumatol. 2015;21:405-10.

19. Li WQ, Han JL, Manson JE, Rimm EB, Rexrode KM, Curhan GC, et al. Psoriasis and risk of nonfatal cardiovascular disease in U.S. women: a cohort study. $\mathrm{Br}$ J Dermatol. 2012;166:811-8.

20. Jamnitski A, Symmons D, Peters MJ, Sattar N, Mclnnes I, Nurmohamed MT. Cardiovascular comorbidities in patients with psoriatic arthritis: a systematic review. Ann Rheum Dis. 2013;72:211-6.

21. Gonzalez-Juanatey C, Vazquez-Rodriguez TR, Miranda-Filloy JA, Dierssen T, Vaqueiro I, Blanco $R$, et al. The high prevalence of subclinical atherosclerosis in patients with ankylosing spondylitis without clinically evident cardiovascular disease. Medicine (Baltimore). 2009;88:358-65.

22. Tam LS, Shang Q, Li EK, Tomlinson B, Chu TT, Li M, et al. Subclinical carotid atherosclerosis in patients with psoriatic arthritis. Arthritis Rheum. 2008;59: 1322-31.

23. Kimhi O, Caspi D, Bornstein NM, Maharshak N, Gur A, Arbel Y, et al. Prevalence and risk factors of atherosclerosis in patients with psoriatic arthritis. Semin Arthritis Rheum. 2007;36:203-9.

24. Gonzalez-Juanatey C, Llorca J, Amigo-Diaz E, Dierssen T, Martin J, GonzalezGay MA. High prevalence of subclinical atherosclerosis in psoriatic arthritis patients without clinically evident cardiovascular disease or classic atherosclerosis risk factors. Arthritis Rheum. 2007;57:1074-80.

25. Bremander A, Petersson IF, Bergman S, Englund M. Population-based estimates of common comorbidities and cardiovascular disease in ankylosing spondylitis. Arthritis Care Res (Hoboken). 2011;63:550-6.

26. Kang $\mathrm{H}$, Chen $\mathrm{YH}$, Lin HC. Comorbidity profiles among patients with ankylosing spondylitis: a nationwide population-based study. Ann Rheum Dis. 2010;69:1165-8.

27. Gulati AM, Semb AG, Rollefstad S, Romundstad PR, Kavanaugh A, Gulati S, et al. On the HUNT for cardiovascular risk factors and disease in patients with psoriatic arthritis: population-based data from the Nord-Trondelag Health Study. Ann Rheum Dis. 2016;75:819-24.

28. Eder L, Zisman D, Barzilai M, Laor A, Rahat M, Rozenbaum M, et al. Subclinical atherosclerosis in psoriatic arthritis: a case-control study. J Rheumatol. 2008;35:877-82.

29. Lindstrom U, Exarchou S, Sigurdardottir V, Sundstrom B, Askling J, Eriksson $J K$, et al. Validity of ankylosing spondylitis and undifferentiated spondyloarthritis diagnoses in the Swedish National Patient Register. Scand J Rheumatol. 2015:44:369-76.

30. Lofvendahl S, Theander E, Svensson A, Carlsson KS, Englund M, Petersson IF. Validity of diagnostic codes and prevalence of physician-diagnosed psoriasis and psoriatic arthritis in southern Sweden-a population-based register study. PLoS One. 2014;9, e98024.

31. Ludvigsson JF, Andersson E, Ekbom A, Feychting M, Kim JL, Reuterwall C, et al. External review and validation of the Swedish national inpatient register. BMC Public Health. 2011;11:450.

32. Holmqvist ME, Neovius M, Eriksson J, Mantel A, Wallberg-Jonsson S, Jacobsson LT, et al. Risk of venous thromboembolism in patients with rheumatoid arthritis and association with disease duration and hospitalization. JAMA. 2012;308:1350-6.

33. Kim SC, Schneeweiss S, Liu J, Solomon DH. Risk of venous thromboembolism in patients with rheumatoid arthritis. Arthritis Care Res (Hoboken). 2013;65:1600-7.

34. Choi HK, Rho YH, Zhu Y, Cea-Soriano L, Avina-Zubieta JA, Zhang Y. The risk of pulmonary embolism and deep vein thrombosis in rheumatoid arthritis: a UK population-based outpatient cohort study. Ann Rheum Dis. 2013:72:1182-7.

35. Grainge MJ, West J, Card TR. Venous thromboembolism during active disease and remission in inflammatory bowel disease: a cohort study. Lancet. 2010;375:657-63.

36. Lee JJ, Pope JE. A meta-analysis of the risk of venous thromboembolism in inflammatory rheumatic diseases. Arthritis Res Ther. 2014;16:435.

37. Feigin VL, Lawes CM, Bennett DA, Anderson CS. Stroke epidemiology: a review of population-based studies of incidence, prevalence, and casefatality in the late 20th century. Lancet Neurol. 2003;2:43-53.

38. Ferro JM. Update on intracerebral haemorrhage. J Neurol. 2006;253:985-99.

39. Andersen KK, Olsen TS, Dehlendorff C, Kammersgaard LP. Hemorrhagic and ischemic strokes compared: stroke severity, mortality, and risk factors. Stroke 2009:40:2068-72.

40. Rothwell PM, Howard SC, Power DA, Gutnikov SA, Algra A, van Gijn J, et al. Fibrinogen concentration and risk of ischemic stroke and acute coronary 
events in 5113 patients with transient ischemic attack and minor ischemic stroke. Stroke. 2004;35:2300-5.

41. Welsh P, Lowe GDO, Chalmers J, Campbell DJ, Rumley A, Neal BC, et al. Associations of proinflammatory cytokines with the risk of recurrent stroke. Stroke. 2008:39:2226-30.

42. Rost NS, Wolf PA, Kase CS, Kelly-Hayes M, Silbershatz H, Massaro JM, et al. Plasma concentration of C-reactive protein and risk of ischemic stroke and transient ischemic attack: the Framingham study. Stroke. 2001;32:2575-9.

43. Anderson Jr FA, Spencer FA. Risk factors for venous thromboembolism. Circulation. 2003;107:19-16.

44. Riva N, Donadini MP, Ageno W. Epidemiology and pathophysiology of venous thromboembolism: similarities with atherothrombosis and the role of inflammation. Thromb Haemost. 2015;113:1176-83.

45. Holst AG, Jensen G, Prescott E. Risk factors for venous thromboembolism: results from the Copenhagen City Heart Study. Circulation. 2010;121:1896-903.

46. Hansson PO, Eriksson H, Welin L, Svardsudd K, Wilhelmsen L. Smoking and abdominal obesity: risk factors for venous thromboembolism among middle-aged men: "the study of men born in 1913". Arch Intern Med. 1999;159:1886-90.

47. Ageno W, Becattini C, Brighton T, Selby R, Kamphuisen PW. Cardiovascular risk factors and venous thromboembolism: a meta-analysis. Circulation. 2008;117:93-102.

48. Tsai AW, Cushman M, Rosamond WD, Heckbert SR, Polak JF, Folsom AR Cardiovascular risk factors and venous thromboembolism incidence: the longitudinal investigation of thromboembolism etiology. Arch Intern Med. 2002;162:1182-9.

49. Glynn RJ, Rosner B. Comparison of risk factors for the competing risks of coronary heart disease, stroke, and venous thromboembolism. Am J Epidemiol. 2005;162:975-82.

50. Mahmoodi BK, Cushman M, Anne Naess I, Allison MA, Jan Bos W, Braekkan SK, et al. Association of traditional cardiovascular risk factors with venous thromboembolism: an individual participant data meta-analysis of prospective studies. Circulation. 2017;135:7-16

51. Willerson JT, Ridker PM. Inflammation as a cardiovascular risk factor. Circulation. 2004;109:II2-10.

52. Holmqvist M, Gransmark E, Mantel A, Alfredsson L, Jacobsson LT, WallbergJonsson $\mathrm{S}$, et al. Occurrence and relative risk of stroke in incident and prevalent contemporary rheumatoid arthritis. Ann Rheum Dis. 2013;72:541-6.

53. Ljung L, Askling J, Rantapaa-Dahlqvist S, Jacobsson L. The risk of acute coronary syndrome in rheumatoid arthritis in relation to tumour necrosis factor inhibitors and the risk in the general population: a national cohort study. Arthritis Res Ther. 2014;16:R127.

54. Ljung L, Simard JF, Jacobsson L, Rantapaa-Dahlqvist S, Askling J. Treatment with tumor necrosis factor inhibitors and the risk of acute coronary syndromes in early rheumatoid arthritis. Arthritis Rheum. 2012;64:42-52.

55. Koster M, Asplund K, Johansson A, Stegmayr B. Refinement of Swedish administrative registers to monitor stroke events on the national level. Neuroepidemiology. 2013;40:240-6.

56. Vaccarino V, Badimon L, Corti R, De Wit C, Dorobantu M, Manfrini O, et al. Presentation, management, and outcomes of ischaemic heart disease in women. Nat Rev Cardiol. 2013;10:508-18.

\section{Submit your next manuscript to BioMed Central and we will help you at every step:}

- We accept pre-submission inquiries

- Our selector tool helps you to find the most relevant journal

- We provide round the clock customer support

- Convenient online submission

- Thorough peer review

- Inclusion in PubMed and all major indexing services

- Maximum visibility for your research

Submit your manuscript at www.biomedcentral.com/submit
C Biomed Central 